\title{
Using Systems Thinking Strategy in an Environment Course
}

\author{
Li-Ting Cheng, Jeng-Fung Hung \\ National Kaohsiung Normal University, \\ Kaohsiung City, Taiwan
}

\author{
Shiang-Yao Liu \\ National Taiwan Normal University, \\ Taipei City, Taiwan
}

\begin{abstract}
This study deals with the development of students' systems thinking skills in a college course. Data were collected to answer the following research questions: 1. What are the factors influencing the development of students' systems thinking ability? and 2. What kinds of relationships are existent among the cognitive components of systems thinking? A general education course, Science and Environment, in which the objectives were established to improve students' abilities for making investigations, evaluating environmental information, and taking environmental actions. Thirty-four college students from various technology-related majors participated in this course. The study was situated in a classroom context; normal assessment practices were used to document students' perceptions about the Bovine Spongiform Encephalopathy (BSE) (the so-called Mad Cow Disease). Analysis of individual student system maps revealed that most students were able to identify the elements of the issue from different perspectives and recognize the operations of and interactions between elements at the beginning of this teaching unit. Results of the post-course assessment showed that the students' systems thinking traits could be categorized in the Levels 4 and 5. In the interviews, the students reflected the drawing of system maps, which could help them consider a complex issue comprehensively and be more considerate while making decisions.
\end{abstract}

Keywords: Bovine Spongiform Encephalopathy (BSE), general education course, systems thinking

\section{Introduction}

One of the goals of university general education is to enhance students' higher-order thinking. Environmental education is the process of concept cognition and value clarification, which focuses on the cultivation of attitudes and the problem-solving ability. Issues instruction features real-time and critical characteristics, which involve the ethical, social, economic, and cultural aspects while the issue-based inquiry process is the formation of value beliefs and the cultivation of problem knowledge and action strategies. Systems thinking is to explore and analyze problems in order to find the problem-related factors and the interactions among the factors. In addition, by exploring the operational and evolutionary processes of factors as well as the interactions among the factors, system operation models and possible evolution models can be established. Both the issue-based inquiry and systems thinking involve high-order thinking skills. Therefore, through the systems thinking, the environmental issues can improve the thinking level. In this study, Bovine

Li-Ting Cheng, Ph.D. candidate, Graduate Institute of Science Education and Envirmental Education, National Kaohsiung Normal University.

Jeng-Fung Hung, Ph.D., professor, Graduate Institute of Science Education and Envirmental Education, National Kaohsiung Normal University.

Shiang-Yao Liu, Ph.D., professor, Graduate Institute of Science Education, National Taiwan Normal University. 
Spongiform Encephalopathy (BSE) (the so-called Mad Cow Disease) incidents will be explored to observe how students contemplate on and explore environmental issues through the system and assess whether their thinking levels have been improved, which shall serve as a reference for teaching design amendments.

Unlike the systematic thinking, systems thinking is an extension from the system theory. The system theory is an interdisciplinary theory used to study the abstract and independent contents that exist in the organizational phenomena, size or space, time, and type. Kant mentioned holism, teleology, and category theory in his critical philosophy, which explain the system characteristics of system structures and functions used to adapt to certain intrinsic purposes. A system's overall form not only displays regulated overall content, but also presets the locations of the parts in the entire system. Kant further interpreted knowledge as an orderly and layered whole made up of certain elements. Therefore, the function of thinking is to connect concepts and classify them. That is, the concepts are first classified under the respective systems. In view of this, Ossimitz (2001) summarized five characteristics of the system: 1. The system includes definable elements; 2 . The elements within the system exist for a common purpose and are therefore correlated; 3. Relative to the environment available, the system should possess a boundary; 4 . The system possesses a dynamic mechanism that can be adjusted with changes in purpose; and 5. A certain element in the system can be regarded as the whole of a sub-system. This being said, a system is a complex yet unified whole made up of a group of interacting, interrelated, and interdependent parts.

Complex systems are an essential focus for science education, because they contain important ideas in national standards and provide an integrating context across a number of science domains (Goldstone \& Wilensky, 2008). Checkland and Poulter (2006) indicated that we all live in the midst of a complex interacting flux of changing events and ideas which unrolls through time. The complexity of problematical situations in real life stems from the facts that not only are they never static; they also contain multiple interacting perceptions of "reality". Systemic thinking, as a conceptual framework of knowledge, principles, and tools, enables observing within the interrelationship and the mutual connections necessary in order to determine changeable patterns and repeated phenomena. Based on an extensive review of the systems thinking literature, Ben-Zvi Assaraf and Orion $(2005 ; 2010)$ summarized eight emergent hierarchic characteristics of systems thinking in the context of earth systems as: (a) the ability to identify the components of a system and processes within the system; (b) the ability to identify relationships among the system's components; (c) the ability to organize the systems' components and processes within a framework of relationships; (d) the ability to make generalizations; (e) the ability to identify dynamic relationships within the system; (f) the ability to understand the hidden dimensions of the system; (g) the ability to understand the cyclic nature of systems; and (h) thinking temporally: retrospection and prediction. It presents the development of systems thinking in the context of earth systems education as occurring in three sequential levels, arranged in a hierarchical pyramid structure. The three levels are: (a) analysis of system components (characteristic 1); (b) synthesis of system components (characteristics 2, 3, 4, and 5); and (c) implementation (characteristics 6, 7, and 8). Each group of skills (specific level) is used as the basis for the development of the next level's skills.

\section{Methods}

\section{Research Questions}

The purpose of this study deals with the development of systems thinking skills at college. It deals with the following research questions: 
1. What are the factors influencing the development of students' systems thinking ability?

2. What kinds of relationships are existent among the cognitive components of systems thinking?

\section{Sample}

The subjects under observation in this study include students that took the Science and Environment course. A total of 34 students who were enrolled in this class engaged in group discussions, practical surveys, and teaching activities. The students majored in optics and communication engineering, software engineering, electronic engineering, industrial design, biotechnology, and chemistry at universities of technology and institutes of science in technology.

\section{Systems Thinking Assessment Standards}

According to the assessment standards formulated based on the teaching goals, the eight classes of systems thinking proposed by Ben-Zvi Assaraf and Orion (2010) served as a reference, which were amended into five classes to meet the demand for this course:

(a) The ability to identify the components of a system and processes within the system-To find the elements of the Mad Cow Disease incidents and the connection among the elements;

(b) The ability to identify relationships among the system's components-To describe the connection of the elements that constitute the Mad Cow Disease incidents from different aspects, such as the biological aspect, economic aspect, and policy aspect;

(c) The ability to organize the systems' components and processes within a framework of relationships-To identify the scope of the Mad Cow Disease incidents under discussion and the operational methods and interactions among the factors;

(d) The ability to understand the hidden dimensions of the system, such as the influence of the media on the incidents;

(e) Thinking in a time dimension-To understand that the interactions within the system had taken place in the past and that the interactions at present may lead to future events, for example, based on the inspiration drawn from Kuru Disease that had taken place in the past, predicting the influence of the approaches adopted at present to deal with the Mad Cow Disease incidents on the future, and so on.

\section{Data Analysis}

The sources of data included teaching journals, videotapes of teaching, students' assignments and drawings, and interviews. The preliminary analysis data in this study focus on the students' outputs, such as individual and group discussion and note-taking, system analysis diagrams, and so on during learning activities.

\section{Findings and Discussion}

Overall, the students communicated with their peers throughout the activity stages to exchange their ideas on the Mad Cow Disease related problems and record the group discussion results. It has been found from a view of the contents from the systems thinking classes that if the students had independently completed the tasks, they could take into consideration the elements that constituted the Mad Cow Disease incidents from multiple perspectives and find the connection among which (see Table 1). In addition, the elements could be divided into economic, diplomatic, political, scientific, environmental, and media dimensions. Furthermore, the group discussions allowed the students to explore the operational methods and interactions that took place in 
their discussion of the Mad Cow Disease incidents and plot diagrams (see Figure 1), which would allow the peers to understand the incident-related viewpoints under discussion.

Table 1

Students' Understanding of the Mad Cow Disease Incidents

\begin{tabular}{|l|l|}
\hline Systems thinking classes & Group discussion results \\
\hline $\begin{array}{l}\text { The definition of the elements that } \\
\text { constitute the Mad Cow Disease incidents } \\
\text { and the connection among the factors }\end{array}$ & $\begin{array}{l}\text { The Mad Cow Disease cannot be prevented or controlled and is difficult to diagnose; } \\
\text { import and export restrictions; the communication and coordination among countries; } \\
\text { edible offal; affect the development of other industries; changes in economic } \\
\text { structure; the probability of infecting other animals; the human self-interest; media; } \\
\text { feed; processed products; politics; medical technology; medical resources; sense of } \\
\text { crisis; public panic; latency; quarantine methods; bureaucracy; sheep scrapie; new } \\
\text { Creutzfeldt-Jakob disease (CJD); Kuru disease }\end{array}$ \\
\hline $\begin{array}{l}\text { The description of the connection of the } \\
\text { Mad Cow Disease incidents based on } \\
\text { different aspects }\end{array}$ & $\begin{array}{l}\text { (a) Economy and free trade factors; } \\
\text { (b) Diplomatic and political factors; } \\
\text { (c) Scientific factors; } \\
\text { (d) Environmental factors; } \\
\text { (e) Media factors. }\end{array}$ \\
\hline $\begin{array}{l}\text { The organizational system parts, } \\
\text { operational processes, and interactions } \\
\text { under the same framework }\end{array}$ & See Figure 1 \\
\hline Finding the system's hidden dimensions & $\begin{array}{l}\text { (a) Cosmetics, animal gelatin found in foods; } \\
\text { (b) Difficulty in determining the sources of processed foods; } \\
\text { (c) Misleading media; } \\
\text { (d) In violation of the natural laws. }\end{array}$ \\
\hline $\begin{array}{l}\text { Finding the effects of the interactions that } \\
\text { take place within the system in terms of } \\
\text { time and space }\end{array}$ & In violation of the natural laws \\
\hline
\end{tabular}

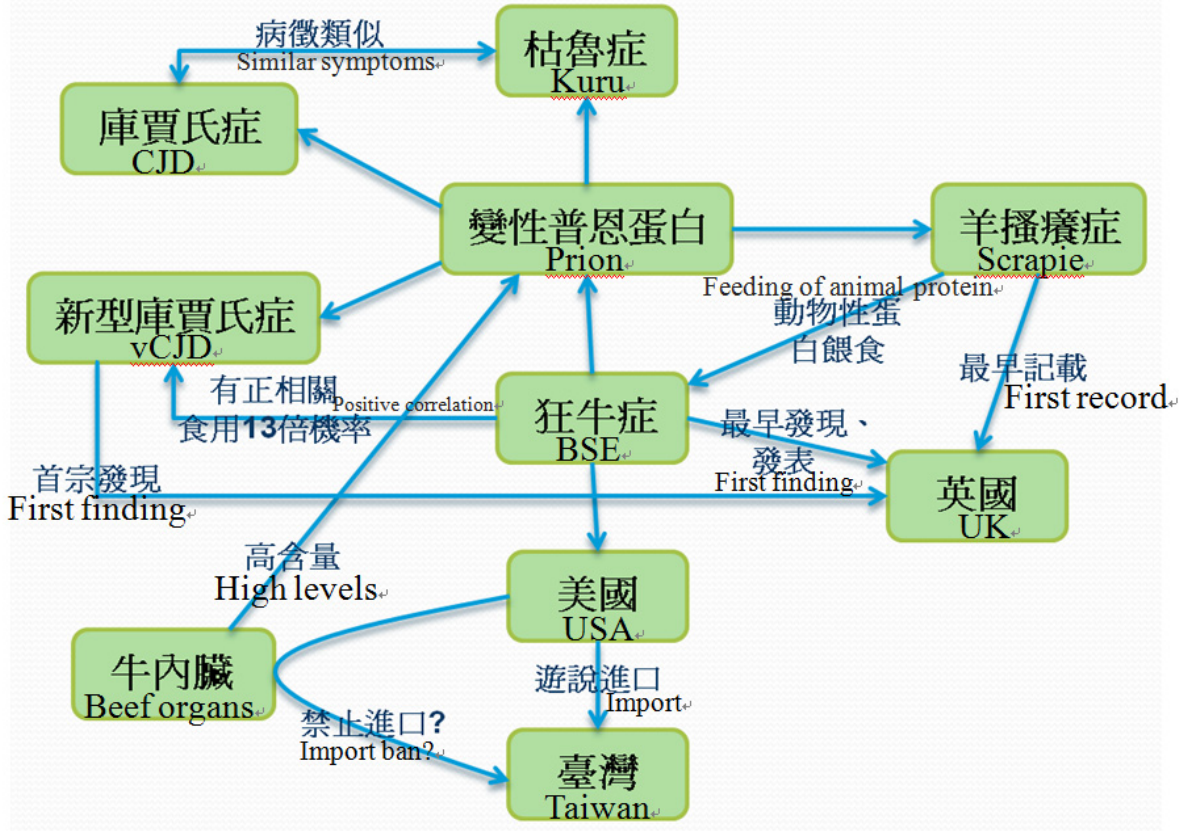

Figure 1. The organizational system parts, operational processes, and interactions under the same framework.

As for the hidden problems in the system that had not been revealed, the groups proposed different problems, many of which included animal gelatin used in foods or other products. However, the effects of the animal gelatin remain unknown. In addition, some groups mentioned the media's "fear the world is not messy 
enough" way of reporting lead to the public's shallow knowledge of the Mad Cow Disease, and thus, the misled public may not be able to make the right decisions. It is worth noting that a group of students said that many technologies are fundamentally in violation of the natural laws in the era of biotechnological advancement and that the Mad Cow Disease is simply a small part of it. As human beings, we ought to think about how we can make a choice between technology and the environment. This viewpoint has also raised questions regarding the effects of the interactions within the system on the past, present, and future time and space, that is, the worry that had been neglected at the time of biotechnological development has resulted in social and environmental problems in the modern times. The effects of these alarming problems on the future ought to be pondered upon during decision-making.

Systems thinking involves many high-order thinking skills, such skills involve a cluster of elaborative mental activities requiring nuance judgment and analysis of complex situations according to multiple criteria. Students should therefore demonstrate abilities to organize the relevant components stated in the organization learning contents and integrate the dynamic processes and interactions. If students have misconceptions about the learning contents (such as the confusion over the concepts of and CJD), they may not be able to successfully explain the connection among the parts within the system. However, through group member interaction, the extent of the students' understanding of the learning contents can be improved.

In the final stage of the learning activities, students had to choose the action strategies for real life. The strategies discussed can be divided into two aspects: For individuals, most of the students chose to stay away from meat while a few students said they only stayed away from the meat parts they had doubt about (such as organs and bone-in beef). In terms of the policy aspect, most of the students believed restricting imports as a feasible approach while some of the students said variant Creutzfeldt-Jakob disease (vCJD) had to be extensively studied to develop vaccines as soon as possible. In addition, the students also deemed the public's correct understanding of the Mad Cow Disease as a feasible solution.

\section{Conclusion}

Contemporary educators have highlighted the importance of environmental education for science and technology education in a broader scope. Growing educational efforts have been paid to prepare environmentally literate students who can make informed decisions on environmental issues and take environmental friendly actions. Considerable research has been carried out in regarding to students' understanding of science concepts related to environmental issues (e.g., Gambro \& Switzky, 1999; Palmer, 1995). Yet, many controversial environmental issues not only have important scientific content associated with it, but also involve non-scientific aspects including social, political, economic and ethical issues (Gayford, 2002). In this study, students reflected that drawing of system maps could help them consider a complex issue comprehensively, and be more considerate while making decisions. Systems thinking strategy could be focused on helping students better deal with the complex, controversial issues, and engaging them in active participation and discussion on the environmental debates.

\section{References}

Ben-Zvi Assaraf, O., \& Orion, N. (2005). Development of system thinking skills in the context of earth system education. Journal of Research in Science Teaching, 42, 518-560.

Ben-Zvi Assaraf, O., \& Orion, N. (2010). System thinking skills at the elementary school level. Journal of Research in Science Teaching, 47, 540-563. 
Checkland, P., \& Poulter, J. (2006). Learning for action: A short definitive account of soft systems methodology, and its use practitioners, teachers and students. Chichester,U.K.: John Wiley \& Sons.

Gambro, J. S., \& Switzky, H. N. (1999). Variables associated with American high school students' knowledge of environmental issues related to energy and pollution. Journal of Environmental Education, 30(2), 15-22.

Gayford, C. (2002). Controversial environmental issues: A case study for the professional development of science teachers. International Journal of Science Education, 24, 1191-1200.

Goldstone, R. L., \& Wilensky, U. (2008). Promoting transfer complex systems principles. Journal of the Learning Sciences, 17, 465-516.

McGregor, D. (2007). Developing thinking; developing learning: A guide to thinking skills in education. New York, N.Y.: Open University Press.

Ossimitz, G. (2001). The development of systems thinking skills. Retrieved from http://www.uniklu.ac.at/users/gossimit/sdyn/gdm _eng.htm

Palmer, D. (1995). The POE in the primary school: An evaluation. Research in Science Education, 25(3), 323-332. 